\title{
Loss of viability during freeze-thaw of intact and adherent human embryonic stem cells with conventional slow-cooling protocols is predominantly due to apoptosis rather than cellular necrosis
}

\author{
Boon Chin Heng ${ }^{1}$, Chao Peng Ye ${ }^{1}$, Hua Liu ${ }^{1}$, Wei Seong Toh ${ }^{1}$, Abdul Jalil \\ Rufaihah $^{2}$, Zheng Yang ${ }^{3}$, Boon Huat Bay ${ }^{4}$, Zigang $\mathrm{Ge}^{1}$, Hong Wei Ouyang ${ }^{5}$, Eng Hin \\ Lee $^{3} \&$ Tong Cao ${ }^{1, *}$ \\ ${ }^{1}$ Stem Cell Laboratory, Faculty of Dentistry, National University of Singapore, 5 Lower Kent Ridge Road, \\ 119074, Singapore, Singapore; ${ }^{2}$ Department of Surgery, Faculty of Medicine, National University of \\ Singapore, 5 Lower Kent Ridge Road, 119074, Singapore, Singapore; ${ }^{3}$ Department of Orthopedic Surgery, \\ Faculty of Medicine, National University of Singapore, 5 Lower Kent Ridge Road, 119074, Singapore, \\ Singapore; ${ }^{4}$ Department of Anatomy, Faculty of Medicine, National University of Singapore, 5 Lower Kent \\ Ridge Road, 119074, Singapore, Singapore; ${ }^{5}$ Tissue Engineering Center, School of Medicine, Zhejiang \\ University, 353 Yan'an Road, Hangzhou, 310031, China
}

Received 22 September 2005; accepted 1 December 2005

(c) 2005 National Science Council, Taipei

Key words: apoptosis, cryopreservation, embryonic, human, stem cells

\section{Summary}

A major challenge in the widespread application of human embryonic stem (hES) cells in clinical therapy and basic scientific research is the development of efficient cryopreservation protocols. Conventional slow-cooling protocols utilizing standard cryoprotectant concentrations i.e. $10 \%(\mathrm{v} / \mathrm{v})$ DMSO, yield extremely low survival rates of $<5 \%$ as reported by previous studies. This study characterized cell death within frozen-thawed hES colonies that were cryopreserved under standard conditions. Surprisingly, our results showed that immediately after post-thaw washing, the overwhelming majority of hES cells were viable $(\approx 98 \%)$, as assessed by the trypan blue exclusion test. However, when the freshly-thawed hES colonies were incubated within a $37^{\circ} \mathrm{C}$ incubator, there was observed to be a gradual reduction in cell viability over time. The kinetics of cell death was drastically slowed-down by keeping the freshly-thawed hES colonies at $4{ }^{\circ} \mathrm{C}$, with $>90 \%$ of cells remaining viable after 90 min of incubation at $4{ }^{\circ} \mathrm{C}$. This effect was reversible upon re-exposing the cells to physiological temperature. The vast majority of low temperature-exposed hES colonies gradually underwent cell death upon incubation for a further 90 min at $37^{\circ} \mathrm{C}$. Terminal deoxynucleotidyl transferase (TdT)-mediated dUTP nick-end-labeling (TUNEL) assay confirmed apoptosis-induced nuclear DNA fragmentation in frozen-thawed hES cells after incubation at $37{ }^{\circ} \mathrm{C}$ for $90 \mathrm{~min}$. Expression of active caspase-3 enzyme, which is another prominent marker of apoptosis, was confirmed by immunocytochemical staining, while transmission electron microscopy showed typical ultrastructural features of apoptosis such as chromatin condensation and margination to the nuclear membrane. Hence, our results demonstrated that apoptosis instead of cellular necrosis, is the major mechanism of the loss of viability of cryopreserved hES cells during freeze-thawing with conventional slow-cooling protocols.

\footnotetext{
*To whom correspondence should be addressed. Fax: +65-6774-5701; E-mail: dencaot@nus.edu.sg
} 


\section{Introduction}

In recent years, human embryonic stem (hES) cells have generated much interest over their potential applications in clinical therapy [1], basic scientific research [2, 3] and for pharmacological and cytotoxicity screening in vitro [4, 5]. Nevertheless, a major bottleneck impeding the widespread application of these cells is the lack of efficient cryopreservation protocols.

Unlike ordinary somatic cells and murine embryonic stem cells, hES cells do not survive well under conventional cryopreservation protocols that utilize standard cryoprotectant concentrations, i.e. $10 \%$ (v/v) dimethyl sulfoxide (DMSO), and slowcooling within a $-20{ }^{\circ} \mathrm{C}$ or $-80{ }^{\circ} \mathrm{C}$ refrigerator [68 , with typically $<5 \%$ of hES cells remaining viable, as reported by previous studies [7, 8]. Although vitrification protocols $[7,8]$ utilizing high cryoprotectant concentrations together with flashfreezing in liquid nitrogen have been reported to yield much higher survival rates; such protocols are tedious to perform manually and are clearly unsuited for handling bulk quantities of hES cells that would almost certainly be required for various clinical and non-clinical applications [6].

Hence, the pertinent question that arises is why hES cells do not take well to conventional cryopreservation protocols? To shed some light on the answer, this study therefore investigated cell-death within hES colonies cryopreserved under standard conditions, i.e. with $10 \%(\mathrm{v} / \mathrm{v})$ DMSO and slowcooling within a $-80{ }^{\circ} \mathrm{C}$ refrigerator. It is hypothesized that cell death from cryopreservation could be induced by two major mechanisms. Firstly, cellular necrosis as a direct result of physical cryoinjury sustained through ice-crystallization or osmotic shock. Secondly, a self-induced apoptotic mechanism may be triggered within hES cells as an indirect result of mild cryoinjury that is not directly lethal to the cell (i.e. damage to gap-junctions, extracellular matrix); or physical environmental stress encountered during cryopreservation (i.e. cold shock, osmotic stress).

If hES cell death during cryopreservation is the direct result of cryoinjury sustained through ice crystallization and osmotic shock, then there would be expected to be an immediate loss of physical integrity of the cell membrane. This in turn is easily detected through trypan blue staining. There would be expected to be a high proportion of non-viable cells being stained blue, immediately after post-thaw washing. By contrast, if a self-induced apoptotic mechanism is involved, then there would be expected to be a gradual loss of cell viability, as the apoptotic cascade would obviously need time to activate and exert its effect on the cell after freeze-thaw. Moreover, the presence of an apoptotic mechanism would be characterized by fragmentation of nuclear DNA [9], which can easily be detected with the terminal deoxynucleotidyl transferase (TdT)mediated dUTP nick-end-labeling (TUNEL) assay [10]; as well as expression of active caspase-3 enzyme, which triggers the self-proteolytic cascade within apoptotic cells [11]. Additionally, chromatin condensation and margination to the nuclear membrane, which are the characteristic morphological features of apoptosis [12] can be viewed under transmission electron microscopy.

Hence, this study sought to determine whether there is an immediate or gradual loss of cell viability upon freeze-thawing of hES colonies cryopreserved with standard protocols. This in turn would be indicative of the major mechanism involved in hES cell death during cryopreservation, i.e. cellular necrosis or apoptosis? Additionally, this study also investigated whether cell death could somehow be abated by keeping the freshlythawed hES cells at low temperature $\left(4^{\circ} \mathrm{C}\right)$. If this is the case, then there would be stronger evidence for an apoptotic mechanism; since the various intracellular enzymes and proteins implicated in the apoptotic cascade would be expected to temporarily lose their activity at low temperature. Finally, the TUNEL assay and immunocytochemical staining for active caspase-3, together with transmission electron microscopy will be used to confirm the presence of apoptosis within frozenthawed hES cells.

\section{Materials and methods}

\section{hES cells, media, reagents and chemicals}

The hES cells were obtained from the Wicell Research Institute Inc. (Madison, WI, USA), and were of the $\mathrm{H} 1$ line listed on the National Institute of Health (NIH) registry, which had received Federal approval for US governmentsupported research funding [13]. Unless otherwise 
stated, all liquid media, serum and serum replacement were purchased from Gibco BRL Inc., (Gaithersburg, MD, USA), while all other reagents and chemicals were purchased from Sigma-Aldrich Inc., (St. Louis, MO, USA).

\section{Culture and propagation of hES cells in the undifferentiated state}

Undifferentiated hES cells were maintained on a feeder layer of mitomycin C-inactivated murine embryonic fibroblast feeder (MEF) cells [14, 15]. These were harvested from the CF1 inbred mouse strain purchased from Charles River Laboratories (Wilmington, MA, USA). The culture medium was DMEM/F12 supplemented with $20 \%$ (v/v) Knockout (KO) serum replacement, $1 \mathrm{mM}$ L-glutamine, $1 \%$ nonessential amino acid, $100 \mathrm{mM} \beta$-mercaptoethanol and $4 \mathrm{ng} / \mathrm{ml} \mathrm{bFGF}$. All cell cultures were carried out on 6-well culture dishes (Nunc Inc., Roskilde, Denmark) within a humidified $5 \% \mathrm{CO}_{2}$ incubator set at $37^{\circ} \mathrm{C}$. The culture media was changed daily with routine passage of hES cells on a fresh MEF layer being carried out once a week. Dissociation of hES colonies into cell clumps for serial passage was achieved through treatment with $1 \mathrm{mg} / \mathrm{ml}$ collagenase type IV, for between 3 and $5 \mathrm{~min}$.

\section{Cryopreservation of intact and adherent hES colonies}

After 4-5 days of culture following the last serial passage, medium-sized adherent hES colonies were cryopreserved by a modified protocol from that recommended by Wicell Inc., [16]. The cryopreservation solution was similar, and consisted of DMEM/F12 medium supplemented with $10 \%$ (v/ v) DMSO and $20 \%(\mathrm{v} / \mathrm{v})$ defined fetal bovine serum. The major difference was that adherent hES colonies were cryopreserved intact on 6-well dishes, instead of dissociated cell-clumps (through collagenase type IV treatment) within cryovials. This was similar to the protocol utilized by a number of previous studies [17-20]. To achieve a gentler drop in temperature within the $-80{ }^{\circ} \mathrm{C}$ refrigerator, the 6-well dishes were placed within an insulated styrofoam box instead of an isoproponal container. A minimal volume of cryopreservation solution $(0.3 \mathrm{ml})$ was added to each well of the dish, just enough to cover the adherent hES colonies. This was to facilitate rapid thawing. The adherent hES colonies cryopreserved on 6-well dishes were stored in the $-80{ }^{\circ} \mathrm{C}$ refrigerator for at least 1 week prior to thawing.

\section{Thawing and post-thaw wash of cryopreserved hES colonies}

Cryopreserved hES colonies on 6-well dishes were thawed for $1-2$ mins within a $37^{\circ} \mathrm{C}$ water bath. Special care was taken to ensure that no water from the bath seeped into the dish during thawing. To minimize osmotic shock to the cells, the thawed cryopreservation solution $(0.3 \mathrm{ml})$ within each well was gradually diluted by dropwise addition of $2 \mathrm{ml}$ of hES culture medium. After that, each well was consecutively washed twice with $2 \mathrm{ml}$ of hES culture media. Depending on the particular experiment, the hES media used for post-thaw wash was either kept at $4{ }^{\circ} \mathrm{C}$ or $37{ }^{\circ} \mathrm{C}$ prior to use.

\section{Effects of temperature on the viability and detachment of frozen-thawed hES colonies}

The freshly-thawed hES colonies were placed either in a $37^{\circ} \mathrm{C}$ incubator, or the $4{ }^{\circ} \mathrm{C}$ chiller compartment of a refrigerator. At different time points (up to 90 mins duration), the viability and detachment of the frozen-thawed hES colonies were assessed by trypan blue staining and observation under bright-field microscopy. Additionally, bright-field images without trypan blue staining were also taken over a time-course of 90 min (Figure 4). All digital images were taken within 5 min of trypan blue staining. Viable cells within the hES colony remained unstained, while non-viable cells were clearly stained blue (Figure 1). Within some of the frozen-thawed hES colonies, some cells began to detach over time, leaving empty patches within the colony (Figure 1). The detached cells were collected by centrifugation, stained with trypan blue and observed under a hemocytometer with brightfield microscopy (Figure 2). It was found that virtually all detached cells were non-viable, as indicated by positive staining (Figure 2). Hence, it can be reasonably assumed that detached areas within hES colonies represented only non-viable cells. 


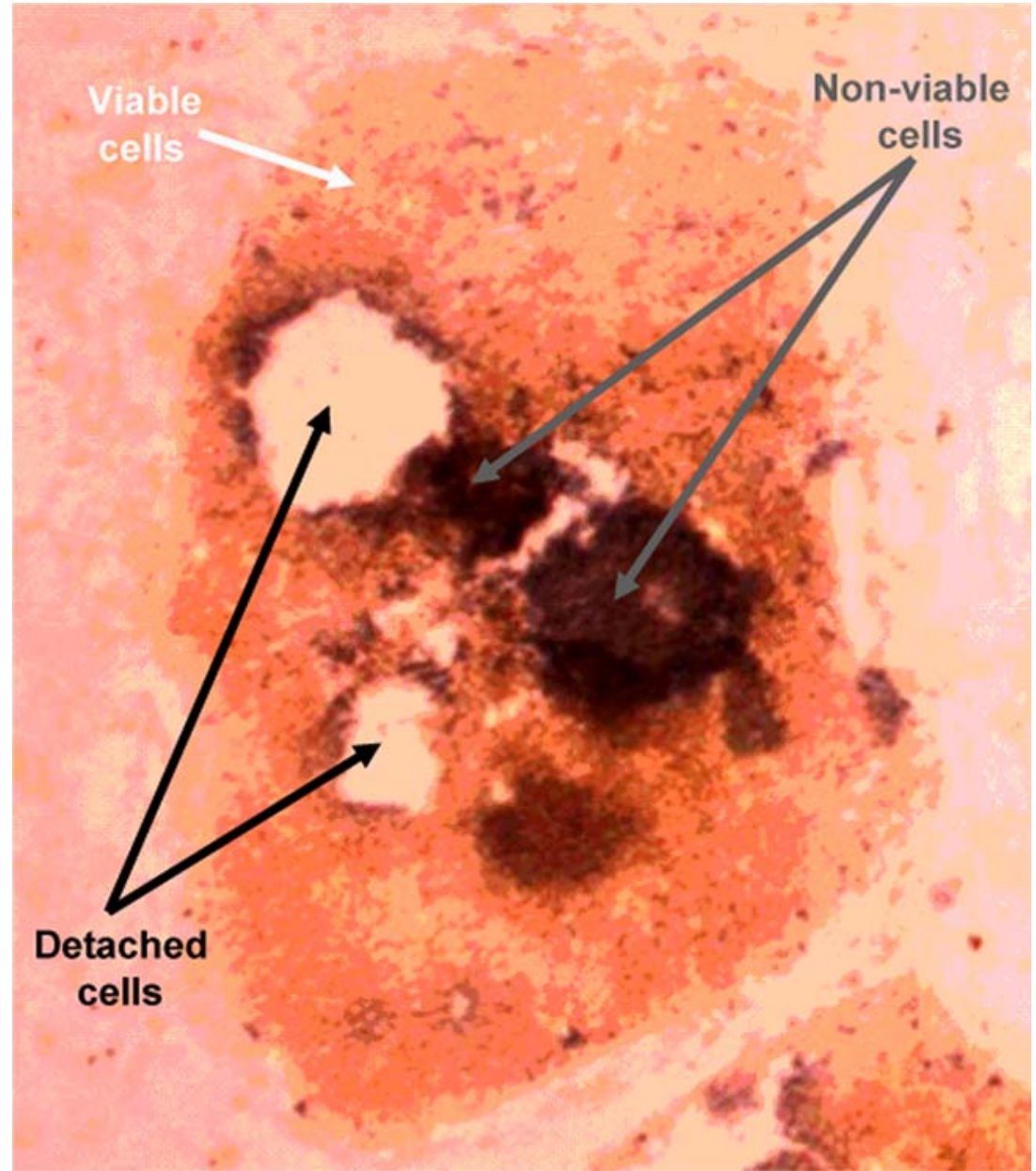

Figure 1. Non-viable cells within frozen-thawed hES colonies are positively stained by trypan blue (grey arrows), while viable cells remain unstained (white arrows). Some of the non-viable cells have detached from the hES colony (black arrows). The image was captured under bright-field microscopy at $40 \times$ magnification.

Assessement of viability and degree of detachment within trypan blue-stained frozen-thawed hES colonies through area analysis

The viability and degree of detachment within trypan blue-stained frozen-thawed hES colonies were determined by area analysis, using ImageTool software (University of Texas Health Science Center, San Antonio, TX, USA). It was assumed that the hES cells were uniformly distributed throughout each colony. The total area occupied by each individual hES colony was first determined, followed by the blue-stained and detached areas within the same colony. This was achieved by manually tracing out the different areas (Figure 3), using the ImageTool software (University of Texas
Health Science Center, San Antonio, TX, USA). The total proportion of non-viable cells was taken to be the combined ratios of blue-stained and detached areas within each hES colony; while the proportion of viable cells was taken to be the ratio of adherent unstained areas within the colony. For each data set, between 20 and 30 trypan bluestained frozen-thawed hES colonies were analysed in this manner.

\section{TUNEL assay for the detection of apoptosis- induced nuclear DNA fragmentation}

After incubating frozen-thawed hES cells at $37{ }^{\circ} \mathrm{C}$ for $90 \mathrm{~min}$, the detached non-viable cells were collected by centrifugation and subjected to TUNEL 


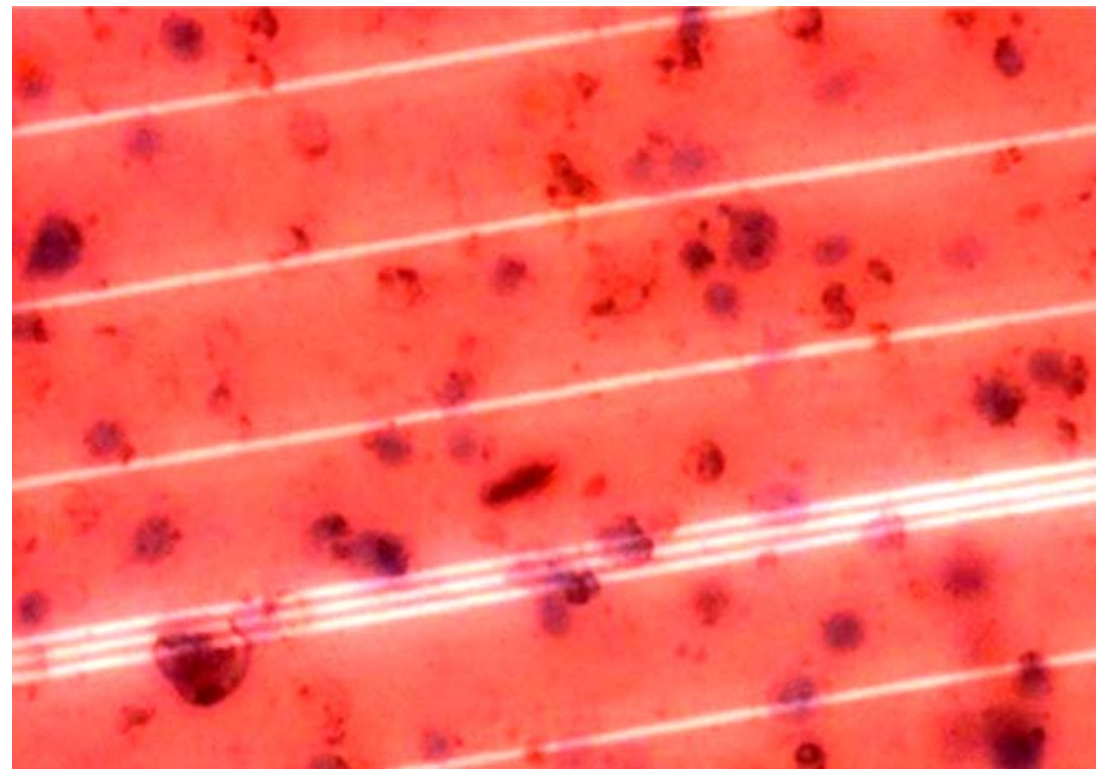

Figure 2. Cells that have detached from hES colonies after freeze-thawing were collected by centrifugation, stained with trypan blue, and observed under a hemocytometer with bright field microscopy at $200 \times$ magnification. Virtually all detached cells were non-viable, as indicated by positive staining.

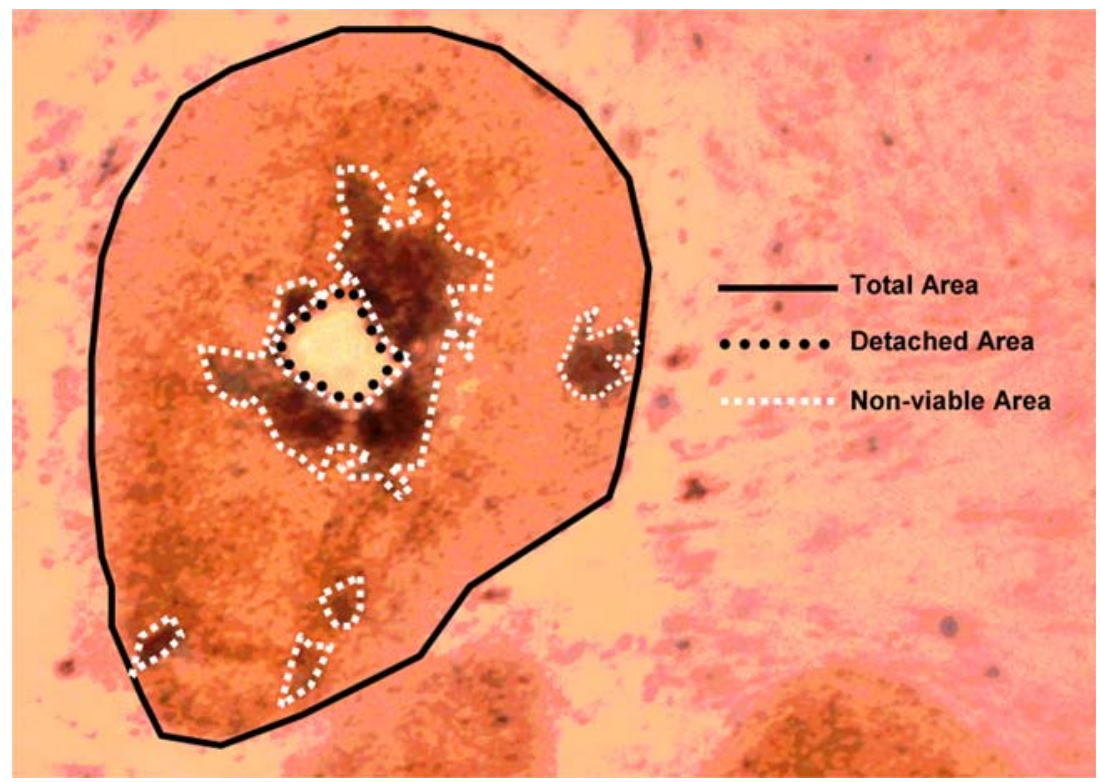

Figure 3. hES colonies were stained with trypan blue, and digital images were captured under bright-field microscopy at $40 \times$ magnification. The total area of each individual hES colony was traced out (black solid line), together with the detached (black dotted line) and non-viable (white dotted line) areas.

assay to detect the presence of apoptosis-induced DNA fragmentation $[9,10]$. The assay was carried out with the BD Apoalert ${ }^{\mathrm{TM}}$ DNA fragmentation assay kit purchased from BD-Biosiences-Clontech Inc., (Mountain View, CA, USA), according to the recommended instructions of the manufacturer. Briefly, this involves fixation of the detached nonviable $\mathrm{hES}$ cells on poly-L-lysine-coated sialized slides with $4 \%(\mathrm{v} / \mathrm{v})$ formaldehyde/PBS at $4{ }^{\circ} \mathrm{C}$ for $25 \mathrm{~min}$. Next, the slides were washed $(3 \times)$ in PBS 

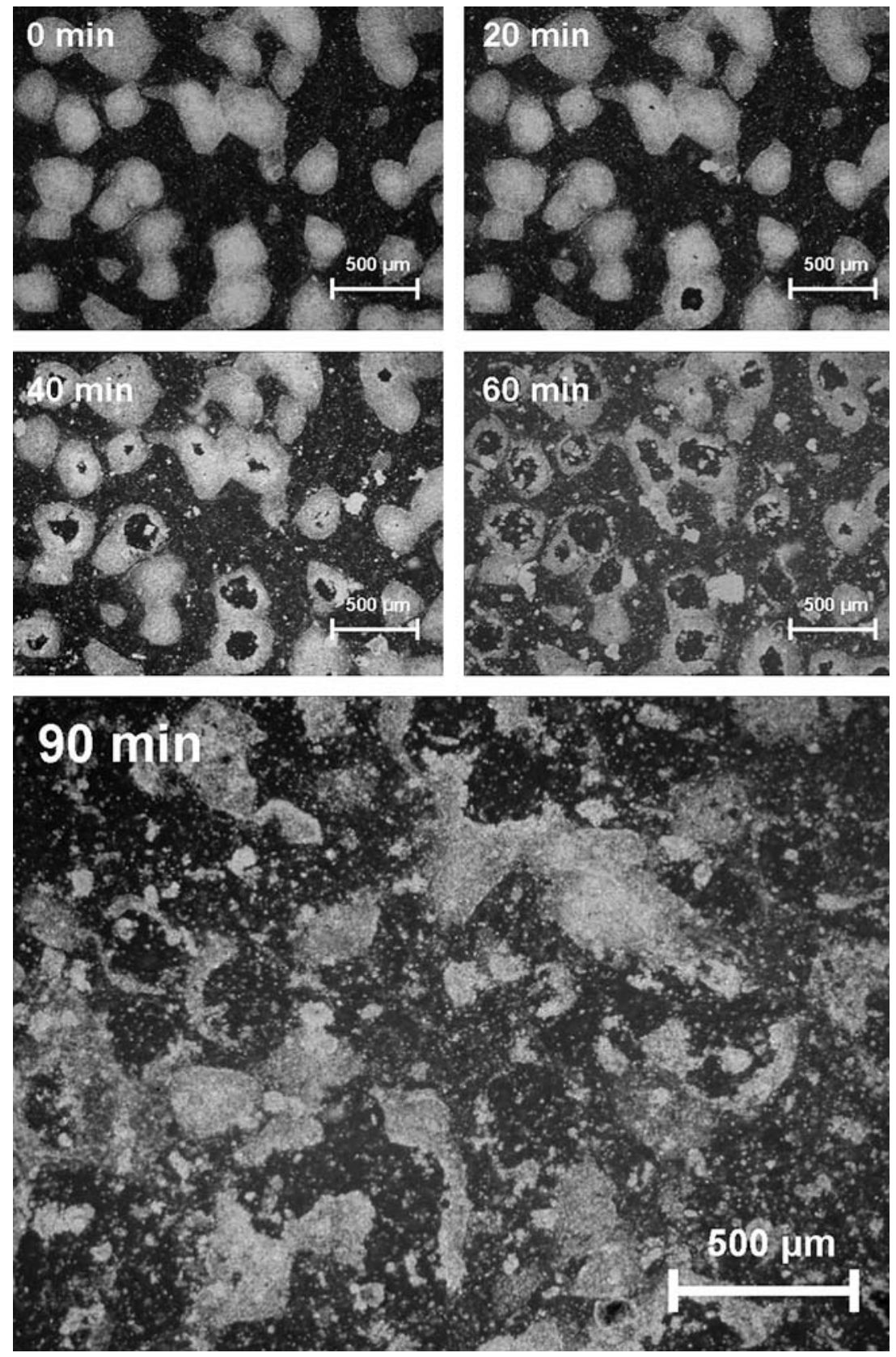

Figure 4. Observations of freshly-thawed cryopreserved hES colonies under bright-field microscopy (without trypan blue staining), incubated at $37^{\circ} \mathrm{C}$ over a time-course of $90 \mathrm{~min}$. By the 90 min time-point, most of the cells within the hES colonies have detached.

before permeabilizing the fixed cells with prechilled $0.2 \%(\mathrm{v} / \mathrm{v})$ Triton X-100/PBS for 5 min on ice. After another round of washing in PBS $(3 \times), 100 \mu 1$ of equilibration buffer $(200 \mathrm{mM}$ Potassium Cacodylate, $25 \mathrm{mM}$ TRIS-HCl, $0.2 \mathrm{mM}$ DTT, $0.25 \mathrm{mg} / \mathrm{ml}$ BSA and $2.5 \mathrm{mM}$ Cobalt Chloride) were placed on the fixed cells for $10 \mathrm{~min}$. Subsequently, the equilibration buffer was pipetted off and the fixed cells were then exposed to $50 \mu \mathrm{l}$ of reaction mix (consisting of the terminal deoxynucleotidyl transferase (TdT) enzyme with fluorescently-labelled nucleotides in equilibration buffer) for $60 \mathrm{~min}$ at $37^{\circ} \mathrm{C}$ within a 
humidified incubator. A glass cover-slip was used to spread the reaction mix evenly on the fixed cells. After that, the cover-slip was removed and the slides were washed in PBS $(3 \times)$ before immediate viewing under fluorescence microscopy. The incorporation of fluorescently-labeled nucleotides within fragmented nuclear DNA was indicated by green-fluorescence at an excitation wavelength of $520 \mathrm{nM}$.

\section{Immunocytochemical staining to detect expression} of active caspase-3 enzyme

After incubating frozen-thawed hES cells at $37{ }^{\circ} \mathrm{C}$ for $90 \mathrm{~min}$, the detached non-viable cells were collected by centrifugation and fixed on poly-L-lysine-coated sialized slides with $4 \%$ (v/v) formaldehyde/PBS at $4{ }^{\circ} \mathrm{C}$ for $25 \mathrm{~min}$. Next, the slides were washed $(3 \times)$ in PBS before permeabilizing the fixed cells with prechilled $0.2 \%(\mathrm{v} / \mathrm{v})$ Triton X100/PBS for $5 \mathrm{~min}$ on ice. After another round of washing in PBS $(3 \times)$, the slides were exposed to blocking buffer (1\% BSA in PBS) for $30 \mathrm{~min}$ at $37{ }^{\circ} \mathrm{C}$, so as to minimize non-specific adsorption of the antibodies. Subsequently, the slides were washed again with PBS $(3 \times)$, and the fixed cells were incubated with primary antibodies against active caspase- 3 enzyme (Rabbit $\mathrm{IgG}, 10 \mu \mathrm{g} / \mathrm{ml}$, Becton-Dickinson Biosciences Inc., San Jose, CA, USA; Cat No: 550480) for $1 \mathrm{~h}$ at room temperature. A glass cover-slip was used to spread the primary antibody solution evenly on the fixed cells. Subsequently, the cover-slip was removed and the slides were washed in PBS $(3 \times)$ before incubation with the secondary antibody (FITCconjugated goat anti-rabbit IgG, $10 \mu \mathrm{g} / \mathrm{ml}$, SigmaAldrich Inc., St. Louis, MO, USA; Cat No: F-0382) under the same conditions. After a final wash in PBS, the slides were viewed under fluorescence microscopy under an excitation wavelength of $488 \mathrm{~nm}$. Positive expression of active caspase- 3 enzyme by the frozen-thawed hES cells was indicated by bright green fluorescence.

\section{Transmission electron microscopy}

After incubating frozen-thawed hES cells at $37^{\circ} \mathrm{C}$ for $90 \mathrm{~min}$, the detached non-viable cells were collected by centrifugation and subsequently fixed with $3 \%$ glutaraldehyde and $2 \%$ paraformaldehyde in $0.1 \mathrm{M}$ cacodylate buffer for $30 \mathrm{~min}$ at room temperature. After osmication in $2 \%$ osmium tetroxide, specimens were dehydrated in an ascending series of ethanol and embedded in araldite. Ultrathin sections were cut, mounted on formvar-coated copper grids, and doubly stained with uranyl acetate and lead citrate before viewing in a Phillips BioTwin CM120 transmission electron microscope (Phillips Electron Optics, Eindhoven, The Netherlands).

\section{Statistical analysis of data}

The results from each data set were expressed as mean \pm standard derivations (computed from area analysis of a total of 20-30 hES colonies). Differences between data sets were assessed by ANOVA analysis, with a value of $p<0.05$ being considered significantly different.

\section{Results}

Kinetics of cell death and detachment within frozen-thawed hES colonies incubated at $37^{\circ} \mathrm{C}$ and $4{ }^{\circ} \mathrm{C}$

Just after the post-thaw wash at the 5 min timepoint, it was observed that $97-98 \%$ of hES cells were viable, as assessed by the trypan-blue exclusion test (Figure 5), irregardless of whether the cells were washed in media pre-kept at $4{ }^{\circ} \mathrm{C}$ or $37^{\circ} \mathrm{C}$. However, when the freshly-thawed hES cells were placed in a $37{ }^{\circ} \mathrm{C}$ incubator, there was observed to be a steep decrease in cell viability over time. This is evident under bright-field microscopy even without trypan blue staining, whereupon a large proportion of the cells detached from the freshly-thawed hES colonies over a time-course of 90 min (Figure 4). By the $90 \mathrm{~min}$ time-point, only $27.3 \pm 10.7 \%$ remained viable (Figure 5). By contrast, when the cells were kept at $4{ }^{\circ} \mathrm{C}$, there was only a slight decrease in cell viability over the same duration, with $90.6 \pm 4.1 \%$ of cells still remaining viable after $90 \mathrm{~min}$ (Figure 5). At all corresponding timepoints except the $5 \mathrm{~min}$ time-point, there were significant differences in the cell viability of hES colonies maintained at $4{ }^{\circ} \mathrm{C}$ and $37^{\circ} \mathrm{C}(p<0.01)$.

Additionally, a vast difference in the kinetics of cell-detachment within hES colonies maintained at $4{ }^{\circ} \mathrm{C}$ and $37^{\circ} \mathrm{C}$ was also observed (Figure 6). Just after the post-thaw wash at the 5 min time-point, virtually none of hES cells detached, irregardless 
$\%$ Viabilty of hES colonies after freeze-thaw, when incubated at $4^{\circ} \mathrm{C}$ and $37^{\circ} \mathrm{C}$

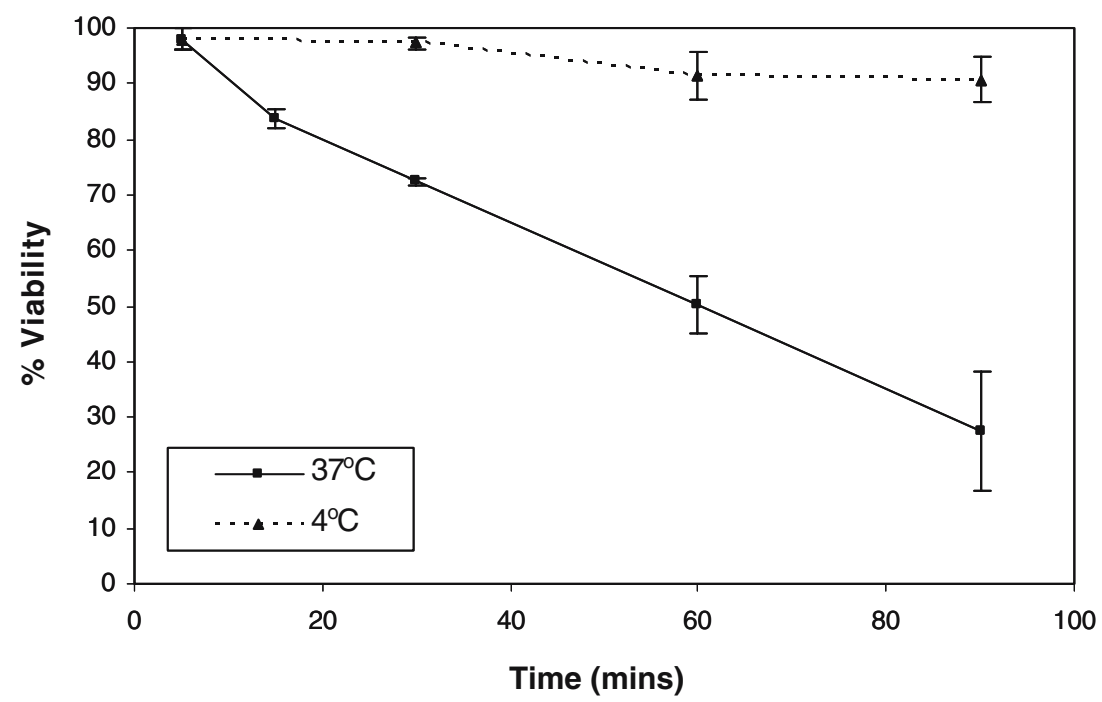

Figure 5. The percentage viability of hES colonies incubated at $4{ }^{\circ} \mathrm{C}$ and $37{ }^{\circ} \mathrm{C}$ was assessed by trypan blue staining and bright field microscopy, over a time course of $90 \mathrm{~min}$.

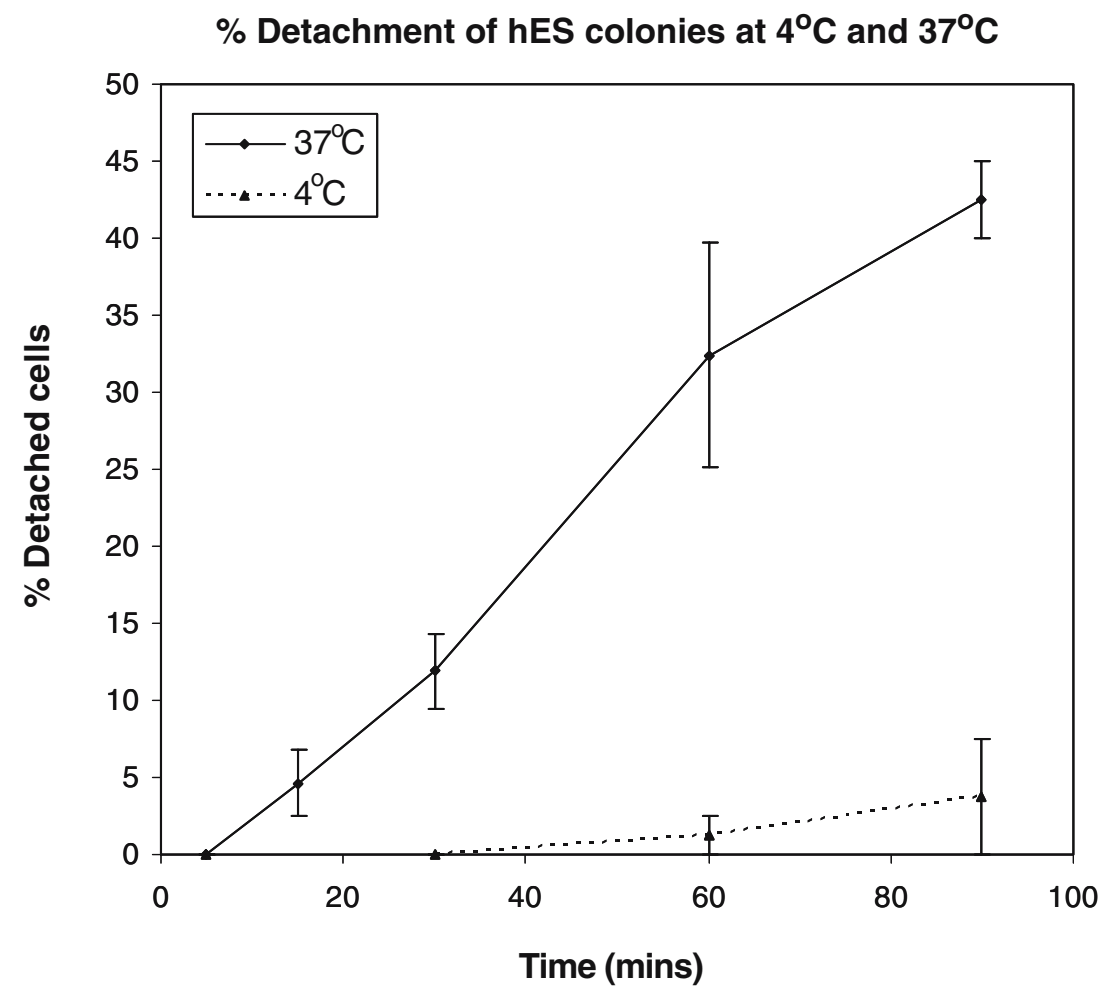

Figure 6. The percentage detachment of hES colonies incubated at $4{ }^{\circ} \mathrm{C}$ and $37{ }^{\circ} \mathrm{C}$ was assessed by bright field microscopy, over a time course of $90 \mathrm{~min}$. 
of whether the cells were washed in media pre-kept at $4{ }^{\circ} \mathrm{C}$ or $37^{\circ} \mathrm{C}$. However, when the freshlythawed hES cells were placed in a $37{ }^{\circ} \mathrm{C}$ incubator, there was observed to be a steep increase in cell detachment over time. By the 90 min time-point, $42.5 \pm 2.4 \%$ of cells within hES colonies have detached (Figure 6). By contrast, when the cells were kept at $4{ }^{\circ} \mathrm{C}$, there was only a slight increase in cell-detachment over the same duration, with $4.1 \pm 3.0 \%$ of cells being detached after $90 \mathrm{~min}$ (Figure 6). At all corresponding time-points except the 5 min time-point, there were significant differences in cell-detachment of hES colonies maintained at $4{ }^{\circ} \mathrm{C}$ and $37{ }^{\circ} \mathrm{C}(p<0.01)$.

\section{Kinetics of cell death and detachment within} frozen-thawed hES colonies kept at $4{ }^{\circ} \mathrm{C}$ for $90 \mathrm{~min}$, followed by incubation at $37^{\circ} \mathrm{C}$ for a further $90 \mathrm{~min}$

After incubation for $90 \mathrm{~min}$ at $4{ }^{\circ} \mathrm{C}$, it was observed that $90.6 \pm 4.1 \%$ of hES cells were viable, as assessed by the trypan-blue exclusion test (Figure 7). However, when the low temperatureexposed hES cells were placed within a $37^{\circ} \mathrm{C}$ incubator, there was observed to be a steep decrease in cell viability over time (Figure 7). After a further $90 \mathrm{~min}$ incubation at $37^{\circ} \mathrm{C}$, only $38.1 \pm 6.8 \%$ of cells retained their viability
(Figure 7). Additionally, there was also observed to be a steep increase in cell-detachment, from $3.0 \pm 3.8 \%$ to $53.3 \pm 7.5 \%$ of cells being detached, after $90 \mathrm{~min}$ of further incubation at $37^{\circ} \mathrm{C}$.

TUNEL assay on frozen-thawed hES cells after 90 min of incubation at $37^{\circ} \mathrm{C}$

After incubation for $90 \mathrm{~min}$ at $37{ }^{\circ} \mathrm{C}$, detached hES cells that appeared non-viable were fixed on slides and subjected to the TUNEL assay. The results (Figure 8) indicated that the nuclei of the fixed cells were positively incorporated with fluorescentlylabeled nucleotides through the action of the TdT enzyme, as indicated by bright green fluorescence under an excitation wavelength of $520 \mathrm{~nm}$. This would mean that the nuclear DNA of the frozenthawed hES cells were fragmented, which clearly indicated that apoptosis has taken place.

Immunocytochemical staining for detection of active caspase-3 enzyme expression by frozenthawed hES cells

After incubation for $90 \mathrm{~min}$ at $37{ }^{\circ} \mathrm{C}$, detached hES cells that appeared non-viable were fixed on slides and subjected to immunocytochemical staining for detection of active caspase-3 enzyme expression. The results (Figure 9) indicated that

\section{$\%$ Viabilty and detachment of frozen-thawed hES colonies after exposure to $4^{\circ} \mathrm{C}$ for 90 mins, followed by incubation at $37^{\circ} \mathrm{C}$ for a time course of a further $90 \mathrm{mins}$}

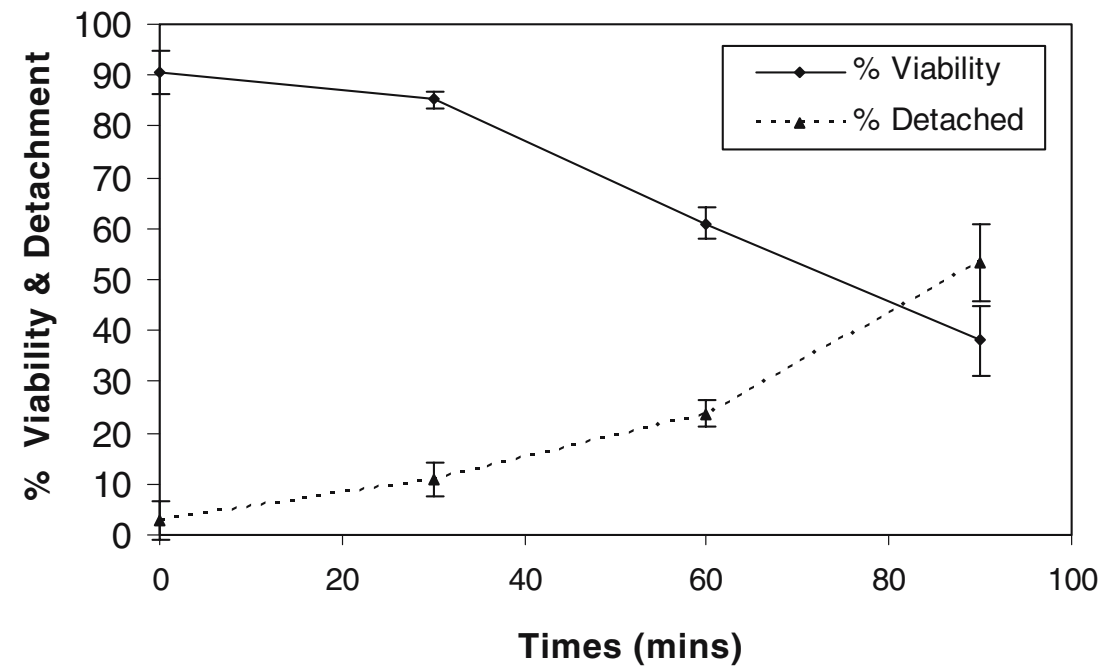

Figure 7. The percentage viability and detachment of hES colonies initially exposed to $4{ }^{\circ} \mathrm{C}$ for 90 min, followed by a further $90 \mathrm{~min}$ of incubation at $37^{\circ} \mathrm{C}$, was assessed by trypan blue staining and bright field microscopy. 

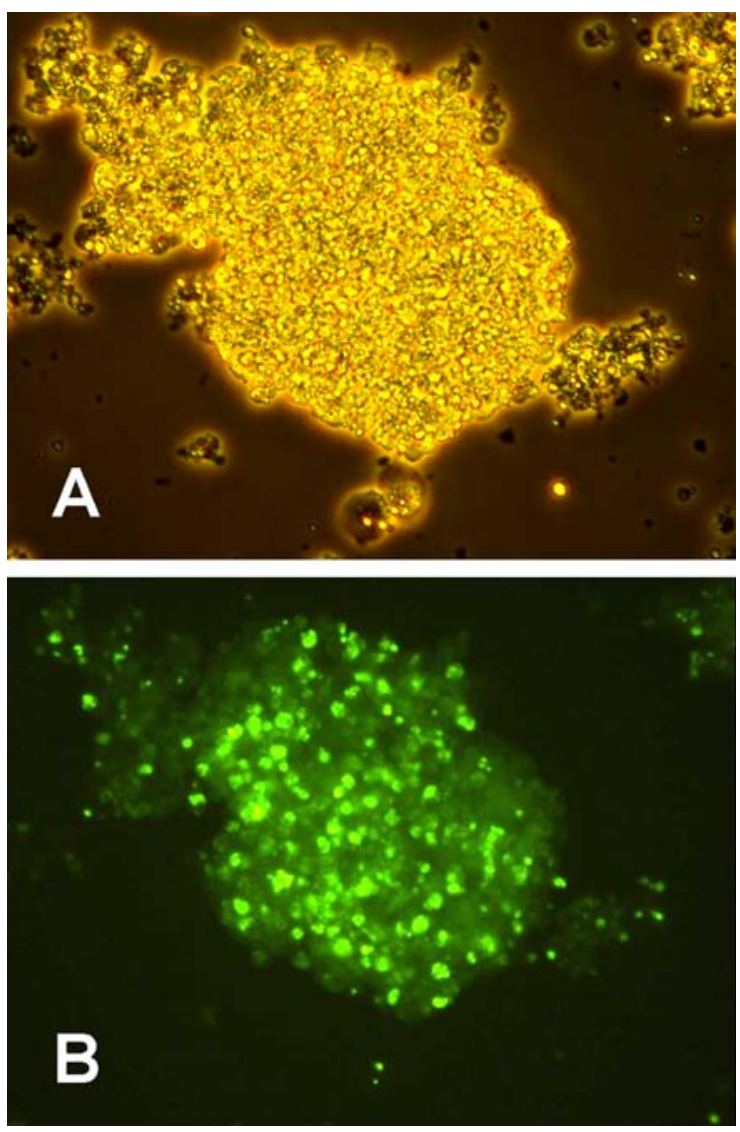

Figure 8. Results of TUNEL assay on frozen-thawed hES cell after $90 \mathrm{~min}$ of incubation at $37^{\circ} \mathrm{C}$. (a) Phase-contrast microscopy at $200 \times$ magnification, (b) Fluorescence microscopy at $200 \times$ magnification, under an excitation wavelength of $520 \mathrm{~nm}$.

the cytoplasm of the fixed cells were strongly expressing active caspase-3 enzyme, as indicated by bright green fluorescence under an excitation wavelength of $488 \mathrm{~nm}$. This would mean that selfproteolysis activated by the caspase- 3 enzyme had occurred within the frozen-thawed hES cells. This is a prominent hallmark of apoptosis [11].

\section{Transmission electron microscopy}

After incubating frozen-thawed hES cells at $37{ }^{\circ} \mathrm{C}$ for $90 \mathrm{~min}$, the detached non-viable cells were fixed and subjected to transmission electron microscopy. The results (Figure 10) showed the typical morphological features of apoptosis [12] such as chromatin condensation and margination to the nuclear membrane (Figure 10a and b), which was notably absent in non-cryopreserved cells (Figure 10c).

\section{Discussion}

In the previous study of Ji et al. [20], adherent hES colonies were cryopreserved intact on 6-well dishes, utilizing conventional slow-cooling with a standard cryoprotectant concentration of $10 \%(\mathrm{v} / \mathrm{v})$ DMSO. In the absence of matrigel and trehalose loading, it was demonstrated that only a very small fraction of cells within intact adherent hES colonies survived freeze-thawing; typically $<5 \%$, which was comparable to the post-thaw recovery rate of enzymatically-dispersed hES cell-clumps cryopreserved within cryovials. Subsequently, Ji et al. [20] showed that matrigel embedment together with trehalose loading of the cells prior to cryopreservation, substantially enhanced post-thaw survival rates of adherent hES colonies. Nevertheless, the study of Ji et al. [20], did not attempt to characterize the mechanism responsible for the low post-thaw survival rates of adherent hES colonies cryopreserved without matrigel embedment and trehalose loading. It was somewhat presumed that the absence of matrigel and trehalose loading rendered the cells more vulnerable to cryoinjury induced by ice-crystallization and osmotic shock. This would imply that the major mechanism of hES cell-death during cryopreservation is cellular necrosis induced directly by cryoinjury. This study therefore attempted to investigate the validity of this presumption.

Surprisingly, the results clearly showed that immediately after the post-thaw wash (5 min timepoint), the overwhelming majority of hES cells within adherent colonies were viable $(\approx 98 \%)$, as assessed by the trypan blue exclusion test (Figure 5). However, there was a steep decline in viability when the hES colonies were incubated at $37{ }^{\circ} \mathrm{C}$, which was much less severe at $4{ }^{\circ} \mathrm{C}$ (Figure 5). This slow-down in the kinetics of cell-death at $4{ }^{\circ} \mathrm{C}$ was somewhat reversible. Upon returning to physiological temperature $37^{\circ} \mathrm{C}$, there was again observed to be a steep decline of cell viability over time (Figure 7). These observations strongly challenge the presumption that cellular necrosis induced directly by cryoinjury is the major mechanism of cell death during freeze-thaw of adherent hES colonies. Instead, the results are suggestive of a self-induced apoptotic mechanism [21], since the kinetics of cell-death is so strongly dependent on physiological temperature (Figure 5). This is made even more evident by the observation that the 

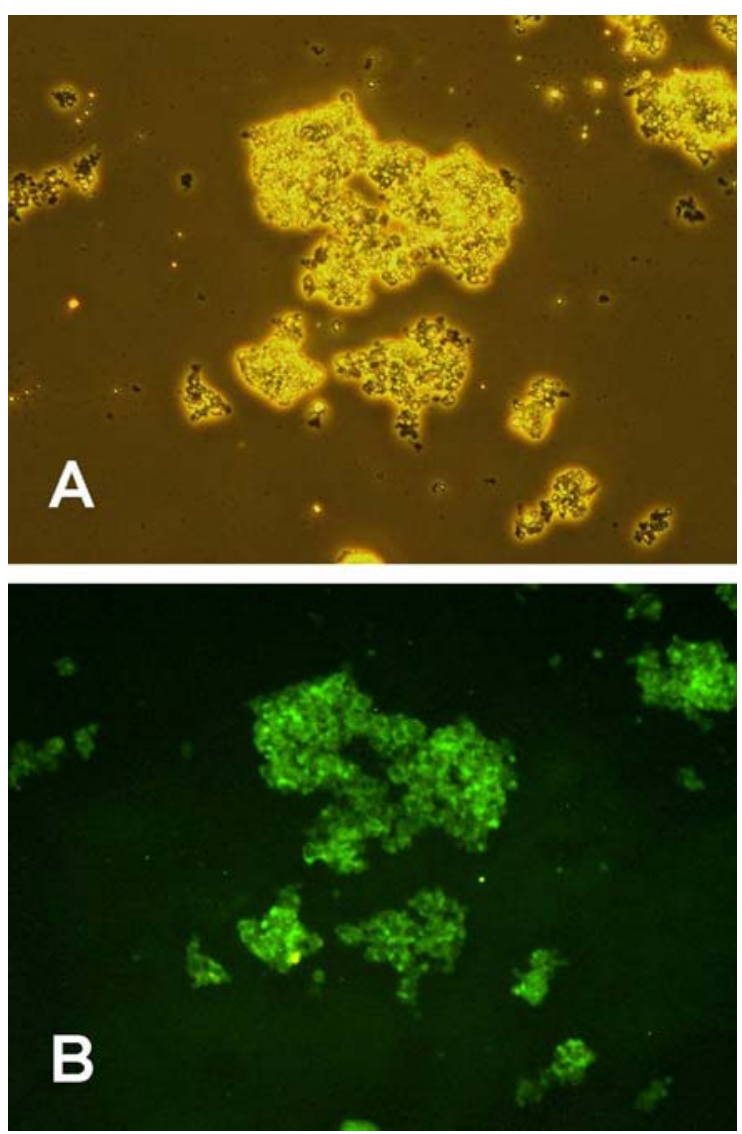

Figure 9. Results of immunocytochemical staining for active caspase- 3 expression by frozen-thawed hES cell after 90 min of incubation at $37^{\circ} \mathrm{C}$. (a) Phase-contrast microscopy at $100 \times$ magnification, (b) Fluorescence microscopy at $100 \times$ magnification, under an excitation wavelength of $488 \mathrm{~nm}$.

slow-down in the kinetics of cell death at low temperature is reversible upon returning to physiological temperature (Figure 7).

Indeed, the result of the TUNEL assay (Figure 8) provides clear evidence for nuclear DNA fragmentation within frozen-thawed hES cells after 90 min of incubation at $37^{\circ} \mathrm{C}$, by which time most of the cells would have lost their viability, as indicated by trypan blue staining (Figure 5). Fragmentation of nuclear DNA is a well-know hallmark of apoptosis [9, 10]. Moreover, immunostaining revealed positive expression of active caspase-3 enzyme (Figure 9), which is another prominent marker of apoptosis [11]. Subsequently, transmission electron microscopy images revealed typical morphological features of apoptosis [12] such as chromatin condensation and margination to the nuclear membrane (Figure 10).
Hence, these data provide conclusive evidence that the apoptotic machinery is somehow triggered in the hES cells immediately after freeze-thawing, and that this is the major causative mechanism for the loss of cellular viability, as opposed to cellular necrosis arising from cryoinjury.

The pertinent question that arises if a selfinduced apoptotic mechanism is somehow implicated in hES cell death during cryopreservation; is why should this be abated by matrigel embedment and trehalose loading, as demonstrated by $\mathrm{Ji}$ et al. [20]? A possible conjecture is that in the absence of matrigel embedment and trehalose loading, cryodamage is predominantly localized on extracellular structural elements within hES colonies, i.e. gapjunctions, intercellular adhesional contacts, rather than within the cell itself or its plasma membrane. Being 'social' cells that require co-operative interactions [14, 15, 22-25], hES cells are particularly vulnerable to any damage to gap-junctional and other intercellular adhesional contacts. Nowhere is this better demonstrated than in the routine serial passage of hES colonies. In all culture protocols reported to date [14, 15, 22, 23], special care is always taken to ensure that hES colonies are mildly dissociated into relatively large cell clumps during serial passage. Indeed, it was clearly demonstrated that extensive dissociation (enzymatic or mechanical) of hES colonies into single cells or clusters containing $<10$ cells during serial passage can severely compromise the survival and propagation of hES cell in vitro [15]. A cell clump size of $\approx 100$ cells has been reported to be optimal for hES colony growth and propagation [15]. The highly 'co-operative' nature of hES cells is further confirmed by electron-microscopic ultrastructural studies, which showed an abundance of tight and gap-junctions within hES colonies [24], as well as by transcriptome profile analysis [25], which revealed high levels of expression of gap-junction and adhesion proteins (i.e. connexin-43 and claudin-6).

Presumably, matrigel embedment and trehalose loading could somehow mitigate against cryodamage to these gap-junctional and adhesional elements within hES colonies. This in turn led to enhanced post-thaw survival rates, as reported by Ji et al. [20]. We hypothesize that cryodamage to gap-junctional and adhesional elements within hES colonies somehow triggered an apoptotic cascade within individual hES cells. This is clearly evidenced by the positive results of the TUNEL assay (Figure 8) and 

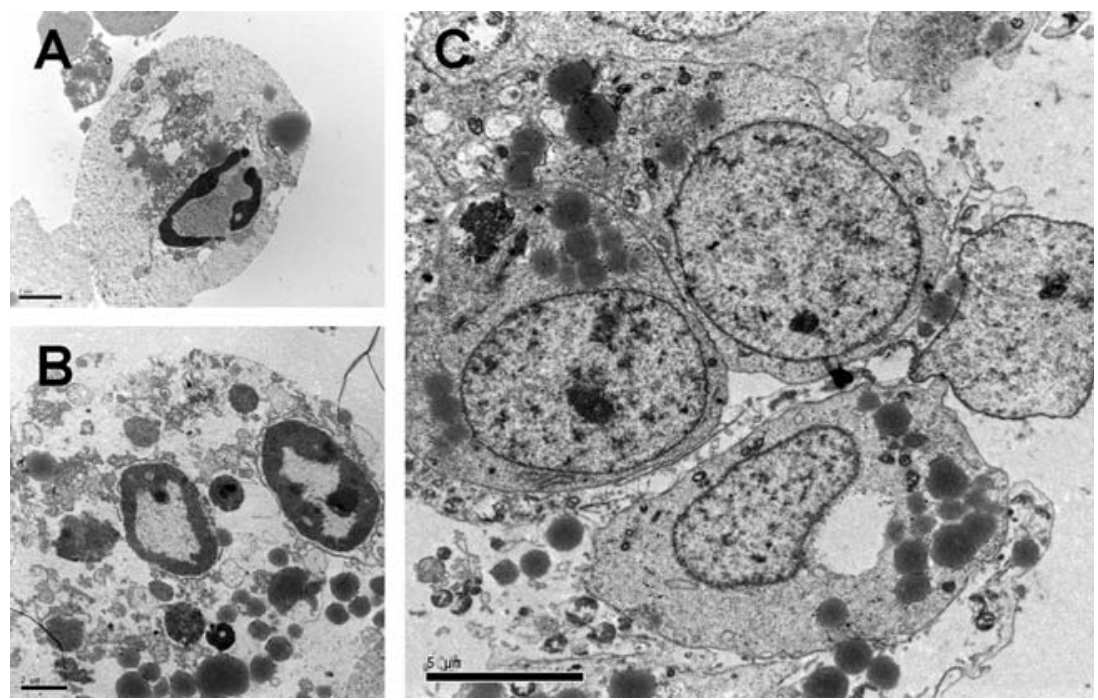

Figure 10. Results of transmission electron microscopy on frozen-thawed hES cell after 90 min of incubation at $37^{\circ} \mathrm{C}$. (a) Early apoptosis with obvious chromatin condensation and margination to the nuclear membrane, (b) Late apoptosis with secondary necrosis, (c) Non-cryopreserved hES cells (negative control) showing uncondensed chromation (speckled appearance of nucleus).

immunocytochemical staining for active caspase-3 expression (Figure 9), together with the distinct morphological features of apoptosis observed under transmission electron microscopy (Figure 10). As would be expected, the various intracellular proteins and enzymes implicated in this putative apoptotic cascade are reversibly and temporarily inhibited by low temperature, as demonstrated by our results (Figure 7). Future work would therefore attempt to investigate the molecular elements of this putative apoptotic cascade.

\section{References}

1. Gerecht-Nir S. and Itskovitz-Eldor J., Cell therapy using human embryonic stem cells. Transpl. Immunol. 12(3-4): 203-209, 2004.

2. Chen D., Lewis R.L. and Kaufman D.S., Mouse and human embryonic stem cell models of hematopoiesis: past, present, and future. Biotechniques 35(6): 1253-1261, 2003.

3. Eisenberg L.M., Kubalak S.W. and Eisenberg C.A., Stem cells and the formation of the myocardium in the vertebrate embryo. Anat. Rec. A Discov. Mol. Cell Evol. Biol. 276(1): 2-12, 2004.

4. Rohwedel J., Guan K., Hegert C. and Wobus A.M., Embryonic stem cells as an in vitro model for mutagenicity, cytotoxicity and embryotoxicity studies: present state and future prospects. Toxicol.s In Vitro. 15(6): 741-753, 2001.

5. Gribaldo L., Alison M., Andrews P.W., Bremer S., Donovan P.J., Knaan-Shanzer S., Mertelsmann R., Spielmann H., Testa N.G., Triffitt J.T., Zipori D. and de Wynter E., Meeting summary: European workshop on stem cells,
European centre for the validation of biomedical testing methods, institute for health and consumer protection, joint research centre, Ispra, Italy, November 21-23, 2001. Exp. Hematol. 30(7): 628-633, 2002.

6. Heng B.C., Kuleshova L.L., Bested S.M., Liu H. and Cao T., The cryopreservation of human embryonic stem cells. Biotechnol. Appl. Biochem. 41(Pt 2): 97-104, 2005.

7. Reubinoff B.E., Pera M.F., Vajta G. and Trounson A.O., Effective cryopreservation of human embryonic stem cells by the open pulled straw vitrification method. Hum. Reprod. 16(10): 2187-2194, 2001.

8. Richards M., Fong C.Y., Tan S., Chan W.K. and Bongso A., An efficient and safe xeno-free cryopreservation method for the storage of human embryonic stem cells. Stem Cells. 22(5): 779-789, 2004

9. Oberhammer F., Wilson J.W., Dive C., Morris I.D., Hickman J.A., Wakeling A.E., Walker P.R. and Sikorska M., Apoptotic death in epithelial cells: cleavage of DNA to $300 \mathrm{and} / \mathrm{or} 50 \mathrm{~kb}$ fragments prior to or in the absence of internucleosomal fragmentation. EMBO J. 12(9): 3679 3684, 1993.

10. Facchinetti A., Tessarollo L., Mazzocchi M., Kingston R., Collavo D. and Biasi G., An improved method for the detection of DNA fragmentation. J. Immunol. Methods 24(136(1): 125-131, 1991.

11. Nicholson D.W., Ali A., Thornberry N.A., Vaillancourt J.P., Ding C.K., Gallant M., Gareau Y., Griffin P.R., Labelle M., Lazebnik Y.A. et al., Identification and inhibition of the ICE/CED-3 protease necessary for mammalian apoptosis. Nature 376(6535): 37-43, 1995.

12. Sheridan J.W., Bishop C.J. and Simmons R.J., Biophysical and morphological correlates of kinetic change and death in a starved human melanoma cell line. J. Cell Sci. 49: 119137, 1981.

13. National Institute of Health (NIH) backgrounder on stem cells. Accessible at: http://www.nih.gov/news/backgrounders/ stemcellbackgrounder.htm. Date Accessed: May 10, 2005. 
14. Thomson J.A., Itskovitz-Eldor J., Shapiro S.S., Waknitz M.A., Swiergiel J.J., Marshall V.S. and Jones J.M., Embryonic stem cell lines derived from human blastocysts. Science 282(5391): 1145-1147, 1998.

15. Reubinoff B.E., Pera M.F., Fong C.Y., Trounson A. and Bongso A., Embryonic stem cell lines from human blastocysts: somatic differentiation in vitro. Nat. Biotechnol. 18(4): 399-404, 2000.

16. Wicell Research Institute Inc. Appendix-Freezing Human Embryonic Stem Cells. Accessible at: http://www.wicell.org/ uploads/media/Freezing_Human_ESC_04.pdf. Date accessed: May 10, 2005.

17. Chan S.Y. and Evans M.J., In situ freezing of embryonic stem cells in multiwell plates. Trends Genet. 7(3): 76, 1991.

18. Ure J.M., Fiering S. and Smith A.G., A rapid and efficient method for freezing and recovering clones of embryonic stem cells. Trends Genet. 8(1): 6, 1992.

19. Udy G.B. and Evans M.J., Microplate DNA preparation, PCR screening and cell freezing for gene targeting in embryonic stem cells. Biotechniques 17(5): 887-894, 1994.
20. Ji L., de Pablo J.J. and Palecek S.P., Cryopreservation of adherent human embryonic stem cells. Biotechnol Bioeng. 88(3): 299-312, 2004

21. Raff M.C., Barres B.A., Burne J.F., Coles H.S., Ishizaki Y. and Jacobson M.D., Programmed cell death and the control of cell survival. Philos. Trans. R. Soc. Lond. B Biol. Sci. 345(1313): 265-268, 1994.

22. Cowan C.A., Klimanskaya I., McMahon J., Atienza J., Witmyer J., Zucker J.P., Wang S., Morton C.C., McMahon A.P., Powers D. and Melton D.A., Derivation of embryonic stem-cell lines from human blastocysts. N. Engl. J. Med. 350(13): 1353-1356, 2004.

23. Amit M., Shariki C., Margulets V. and Itskovitz-Eldor J., Feeder layer- and serum-free culture of human embryonic stem cells. Biol. Reprod. 70(3): 837-845, 2004.

24. Sathananthan H., Pera M. and Trounson A., The fine structure of human embryonic stem cells. Reprod. Biomed. Online. 4(1): 56-61, 2002.

25. Richards M., Tan S.P., Tan J.H., Chan W.K. and Bongso A., The transcriptome profile of human embryonic stem cells as defined by SAGE. Stem Cells. 22(1): 51-64, 2004. 